\title{
Body composition assessment in lean and normal-weight young women
}

\author{
BY G. MIKAEL FOGELHOLM, T. KATRIINA KUKKONEN-HARJULA, \\ HARRI T. SIEVÄNEN, PEKKA OJA AND ILKKA M. VUORI \\ UKK Institute for Health Promotion Research, PO Box 30, FIN-33501 Tampere, Finland
}

(Received 27 September 1994 - Revised 13 April 1995 - Accepted 6 October 1995)

\begin{abstract}
Using percentage body fat (BF \%) from a three-compartment (3C) model (body density from underwater weighing (UWW) and bone-mineral mass from dual-energy $X$-ray absorptiometry (DXA)) as a criterion, we studied the accuracy of UWW, DXA, two skinfold equations, and two bioimpedance (BIA) equations. Thirty-four women (aged 16-20 years) with BF\% 13-5-31.1 volunteered. UWW underestimated BF\% by -0.5 BF \% (95\% CI: - 1.0; - 0.02), whereas DXA overestimated it by 7.3 BF \% (95\% CI 5.8; 8.8$)$. Skinfolds underestimated and BIA overpredicted BF\%. The differences between $3 C$ and UWW, skinfolds (Durnin \& Womersley, 1974) and BIA (Deurenberg et al. 1990) were dependent (range of $r$ values: -0.63 to $-0.79 ; P<0.0001$ ) on $B F \%$, causing an overestimation of lean subjects' (UWW, BIA) or an underestimation of normal-weight subjects' (UWW, skinfolds) BF\%. The $3 \mathrm{C}$ model and UWW gave comparable body-composition results for healthy young women with $\mathrm{BF} \%$ of approximately 20-25. Based on a significant mean difference from the $3 \mathrm{C}$ model, and a large standard error of the estimate, we do not regard DXA as superior to skinfolds or BIA to assess BF \%.
\end{abstract}

Bioimpedance: Body composition: Bone: Dual-energy X-ray absorptiometry

Information about body composition in lean and normal-build young women is needed in clinical and scientific work with, for instance, athletes and patients with eating disorders. Information on body composition is also important in metabolic studies, and for calculating drug dose in pharmaceutical studies. Underwater weighing (UWW) and skinfold measurements are the most frequently used methods in laboratory and field respectively. New alternatives include bioelectrical impedance analysis (BIA), dual-energy X-ray absorptiometry (DXA) and multicompartment models (e.g. UWW and DXA in combination).

Variation in total bone-mineral content (TBMC), especially in young or postmenopausal women, is a major factor affecting the accuracy of UWW (two-compartment model), in which the densities of fat and fat-free compartments are assumed to be constant (Martin \& Drinkwater, 1991). TBMC in women is affected by several factors in early adulthood, such as weight, biological maturation, oestrogen production, nutrient intakes and physical exercise (Suominen, 1993).

Combining values for body density (by UWW) and TBMC yields a three-compartment (3C) model (fat, bone, fat-free soft tissue), in which TBMC from a whole-body DXA scan is used to correct for variation in bone minerals (Lohman, 1986). Body composition can also be assessed using DXA only (Mazess et al. 1990), but to the best of our knowledge the accuracy of this method in young women has not been examined.

Use of skinfolds and BIA to assess $\mathrm{BF} \%$ in young women raises practical problems. For instance, it may be inappropriate to use adult equations which assume a fixed chemical composition of the fat-free compartment or a certain pattern of subcutaneous fat 
distribution (Lohman, 1986; Martin \& Drinkwater, 1991; Webster \& Barr, 1993). In particular adolescent females and athletes favouring lean body image are at risk of eating disorders, and improper use of body composition analysis by, for instance, trainers or teachers might aggravate this problem (Webster \& Barr, 1993). Therefore, more research is needed to examine the validity of skinfolds and BIA in relation to multicompartment models in young women.

Using a 3C model (fat, bone and fat-free soft tissue from UWW and DXA) as the criterion model, we addressed two questions concerning body composition (in the present study: percentage body fat, $\mathrm{BF} \%$ ) assessment in lean and normal-weight young women: (1) how large is the difference between the $3 \mathrm{C}$ model and the alternative methods (UWW, DXA, two skinfold equations, two BIA equations); (2) are the differences dependent on the magnitude of $\mathrm{BF} \%$ ?

\section{METHODS}

Subjects

Thirty-four women volunteered. To obtain a sample with a wide variation in the level and type of physical activity, both non-athletes and athletes were recruited: twelve participants $(35 \%)$ were high-school students not engaged in regular sports training, twelve $(35 \%)$ were gymnasts $(n 9)$ or figure-skaters $(n 3)$ at elite national level, and ten $(30 \%)$ played soccer in a team in the Finnish national league. None of the subjects followed a completely vegetarian diet or was under treatment for a clinical eating disorder. Five subjects were oligomenorrheic (4-9 menstrual cycles during the past year) and two (both aged 16 years) had not reached menarche. Contraceptive pills were used by four subjects.

For the menstruating participants ( $n$ 32) the measurements were done within $14 \mathrm{~d}$ of the start of a menstrual period. The measurements began, after an overnight fast, with BIA, followed by DXA, anthropometry (weight, height, skinfolds) and UWW. Alternatively, anthropometry and UWW were done before DXA. The subjects had a light breakfast (one slice of bread with cheese and one glass of juice) immediately after BIA. All measurements for each participant were finished within $4 \mathrm{~h}$.

The characteristics of the participants were: mean age 17 (range 16-20) years, height 1.65 (range 1.52-1.76) $\mathrm{m}$, weight 55.8 (range 38.9-66.6) $\mathrm{kg}$ and BMI 20.6 (range 16.8$23.8) \mathrm{kg} / \mathrm{m}^{2}$. After being informed about the study, all subjects (or if under 18 years, their guardian) signed a written informed consent. The study was approved by the ethical committee of the UKK Institute for Health Promotion Research, Tampere, Finland.

\section{Underwater weighing}

Before UWW the subject was weighed on a high-precision scale (Sartorius F 150S-D2, Goettingen, Germany) in a swimming-suit. Then the subject was submerged to her neck in a sitting position and the residual lung volume (RV) was determined by the He-dilution method, using a wet spirometer (Pulmonet III, Sensormedics BV, Bilthoven, The Netherlands). Two to four trials were performed to obtain two readings with less than $0 \cdot 1$ litres of difference. RV was the mean of these two values.

The scale for UWW (Tamtron Inc., Tampere, Finland) was connected via a 12-bit A/Dconverter (DT2801, Data Translation Inc., Marlborough, MA, USA) to a microcomputer which continuously acquired weight values at 20 samples/s. The resolution was $2 \cdot 4 \mathrm{~g}$. A dedicated software program was used to record the underwater trials and to calculate the average weight for each trial. All weight measurements were visually verified. The subject performed eight successive underwater trials in a sitting position after full exhalation (presumably at RV) and the mean of the three trials giving the highest results was used in further calculations. Air volume in the gastrointestinal tract was assumed to be $0 \cdot 1$ litres. 


\section{Dual-energy $X$-ray absorptiometry}

TBMC and BF\% were determined with a DXA scanner (XR-26, Norland Corp, Fort Atkinson, WI, USA) that uses an X-ray tube operating at $100 \mathrm{kVp}$ coupled with a multistage K-edge samarinium filter. The two effective energies were 47 and $80 \mathrm{keV}$. Subject position and scanning were done by the same operator and according to the manufacturer's recommendations. The scan speed was $80 \mathrm{~mm} / \mathrm{s}$ and resolution (pixel size) $6.5 \times 13 \mathrm{~mm}^{2}$. Duration of the scan was about $20 \mathrm{~min}$. According to the manufacturer, the precision in vivo of the TBMC measurements is $0.8 \%$. TBMC and $\mathrm{BF} \%$ were calculated from the scan data by the Norland total body composition scan software (versions 2.2.2 and 1.1.4 respectively). The scanner was calibrated daily using a dedicated calibration standard.

\section{Skinfold thickness}

Using Harpenden calipers (British Indicators Ltd, Luton, Beds.), skinfold measurements were taken from the following five sites (Harrison et al. 1991): triceps (posterior aspect of the arm, at the midpoint between the lateral projection of the acromial process and the inferior border of the olecranon process of the ulna), biceps (anterior aspect of the arm, same level as triceps skinfold), subscapula (inferior to the inferior angle of the scapula, $45^{\circ}$ angle), suprailiac (horizontal skinfold at the midaxillary line immediately superior to the iliac crest) and mid-thigh (midpoint between the inguinal crease and the proximal border of patella). The right side of the body was used for all measurements. Three readings (to the nearest $0.1 \mathrm{~mm}$ ) from each site were obtained and the mean value was used in calculations. One technician carried out all measurements.

\section{Bioelectrical impedance}

After an overnight fast and within $30 \mathrm{~min}$ of the last voiding, a standard whole-body rightsided tetrapolar BIA was performed using the RJL BIA-106 analyser (RJL Systems Inc., Detroit, MI, USA) with subjects in a supine position after a $15 \mathrm{~min}$ resting period. The procedure was done as described by Lukaski et al. (1985).

\section{Calculation of percentage body fat}

In addition to the data obtained using DXA software, BF\% was calculated from six different equations:

(1) 3C model, used as the criterion method, with the Lohman (1986) equation:

$$
\mathrm{BF} \%=\left(6.386 / \mathrm{D}_{\mathrm{b}}+3.961 \mathrm{BMF}-6.090\right) \times 100,
$$

where $\mathrm{D}_{\mathrm{b}}$ is body density $\left(\mathrm{g} / \mathrm{cm}^{3}\right)$ from $\mathrm{UWW}$ and $\mathrm{BMF}$ is body mineral fraction $(\mathrm{kg})$, calculated as $(\mathrm{TBMC} /(0.824 \times$ body weight $))$.

(2) UWW (two-compartment model) with the Siri (1956) equation:

$$
\mathrm{BF} \%=\left(4.95 / \mathrm{D}_{\mathrm{b}}-4.50\right) \times 100 .
$$

(3) Skinfolds $\mathrm{JPW}_{\mathrm{JW}}$ with the Jackson et al. (1980) equation:

$$
\mathrm{D}_{\mathrm{b}}=1.0994921-0.0009929 \Sigma \mathrm{S}+0.0000023 \Sigma \mathrm{S}^{2}-0.0000714 \text { age, }
$$

where $\Sigma S$ is sum of triceps, suprailiac and thigh skinfold thicknesses.

(4) Skinfolds ${ }_{\text {Dw }}$ with the Durnin \& Womersley (1974) equation:

$$
\mathrm{D}_{\mathrm{b}}=1 \cdot 1549-0 \cdot 0678(\log \Sigma \mathrm{S}) \text {, }
$$

where $\Sigma S$ is sum of triceps, biceps, subscapular and suprailiac skinfold thicknesses. $\mathrm{BF} \%$ was calculated from $D_{b}$ with the Siri (1956) equation. 
(5) BIA $_{\mathrm{LUK}}$ with the Lukaski et al. (1986) equation:

$$
\mathrm{FFM}=4.917+0.821 \times \text { height }^{2} / \mathrm{R} \text {, }
$$

where FFM is fat-free mass $(\mathrm{kg})$ and $\mathrm{R}$ is resistance $(\Omega)$. Height is expressed in $\mathrm{cm}$.

(6) $\mathrm{BIA}_{\mathrm{DEU}}$ with the Deurenberg et al. (1990) equation:

FFM $=2580 \times$ height $^{2} /$ impedance +0.375 weight +10.5 height -0.164 age -6.5,

where impedance $=\left(\text { resistance }^{2}+\text { reactance }^{2}\right)^{0.5}$. Height is expressed in $\mathrm{m}$. BF\% $=$ $(($ weight - FFM $) /$ weight $) \times 100$.

\section{Statistical analyses}

Method comparisons were done as recommended by Altman \& Bland (1983). The difference between the $3 \mathrm{C}$ and an alternative method was calculated by subtracting the $3 \mathrm{C}$ result from the alternative result. The difference was considered significant when the $95 \%$ CI of the mean difference did not include the zero value. The statistical associations between the magnitude of measurement (average of the $3 \mathrm{C}$ and alternative results) and difference (alternative minus $3 \mathrm{C}$ ), and between the $3 \mathrm{C}$ and alternative results were calculated by Pearson product-moment correlations. Standard error of the estimate was calculated as SEE $=\mathrm{SD}_{3 \mathrm{C}} \times\left(1-r^{2}\right)^{0.5}$, where $\mathrm{SD}_{3 \mathrm{C}}$ is the $\mathrm{SD}$ of the $3 \mathrm{C}$ model and $r$ is the correlation coefficient between the $3 \mathrm{C}$ model and the alternative method (Clark et al. 1993). BMDP Statistical Software (BMDP Statistical Software Inc., Los Angeles, CA, USA) (1990 version) was used for statistical analyses. The $95 \%$ CI for mean values and for correlation coefficients were calculated according to Gardner \& Altman (1989).

\section{RESULTS}

Mean values, 95\% CI for the mean and ranges for body density, TBMC, skinfold thicknesses and impedance index (height ${ }^{2} /$ resistance) are presented in Table 1 . The mean $\mathrm{BF} \%$, calculated by $3 \mathrm{C}$, was $22 \cdot 7$, with a range from 13.5 to $31 \cdot 1$ (Table 2 ). The mean $\mathrm{BF} \%$ values of alternative methods varied between 17.2 (skinfolds (sw $_{\text {) }}$ and 30.0 (DXA). All alternative methods were significantly different $(P<0.05)$ from the $3 \mathrm{C}$ model (Table 2$)$. However, the difference between UWW (two-compartments) and the $3 \mathrm{C}$ model was only $0.5 \mathrm{BF} \%(2 \cdot 2 \%)$.

UWW gave higher results than the $3 \mathrm{C}$ model for the lean and lower results for the normal-weight volunteers (Fig. 1(a)): the correlation coefficient between the magnitude of measurement and the difference between the models was $r-0.63(95 \% \mathrm{CI}:-0.37 ;-0.80$, $P=0.0001$ ). The mean $\mathrm{BF} \%$ values for subjects with a $3 \mathrm{C}$ model result below $20 \%$ were 16.6 and 16.2 for UWW and $3 C$ respectively. For subjects with a $3 C$ result above $25 \%$, the corresponding results were $27 \cdot 1$ and $29 \cdot 1$.

The difference between the $3 \mathrm{C}$ model and the skinfolds $\mathrm{Dw}_{\mathrm{DW}}$, and that between the $3 \mathrm{C}$ model and the $\mathrm{BIA}_{\mathrm{DEU}}$ were also dependent on the magnitude of measurement: $r-0.75$ (95\% CI: $-0.87 ;-0.56, P<0.0001)$ and $-0.79(95 \% \mathrm{CI}:-0.89 ;-0.61, P<0.0001)$ for skinfolds $_{\mathrm{DW}}$ and $\mathrm{BIA}_{\mathrm{DEU}}$ respectively (Fig. 1(b) and 1(c)). Although both correlations were negative, the relation to zero difference was dissimilar: for skinfolds ${ }_{\mathrm{DW}}$, underprediction was greater with increasing $\mathrm{BF} \%$, whereas for $\mathrm{BIA}_{\mathrm{DEU}}$, overprediction increased with decreasing $\mathrm{BF} \%$.

The difference between the $3 \mathrm{C}$ model and DXA, skinfolds $\mathrm{JPW}_{\mathrm{JPW}}$ or BIA $\mathrm{LUK}_{\mathrm{LU}}$ was independent of the magnitude of the measurements (range of $r$ values : $0.06-0.25, P=0.14-0.76$ ). Hence, 
Table 1. Body density, mineral content, skinfold thickness and bioimpedance values used in the assessment of body composition in thirty-four young women

\begin{tabular}{|c|c|c|c|}
\hline & Mean & $95 \% \mathrm{CI}$ & Range \\
\hline \multicolumn{4}{|l|}{ Underwater weighing } \\
\hline Body density $\left(\mathrm{g} / \mathrm{cm}^{3}\right)$ & 1.048 & $1.045 ; 1.051$ & $1.030-1.067$ \\
\hline \multicolumn{4}{|l|}{ DXA } \\
\hline TBMC (kg) & $2 \cdot 614$ & $2 \cdot 500 ; 2 \cdot 728$ & $1 \cdot 693-3 \cdot 211$ \\
\hline Body mineral fraction* & 5.69 & $5 \cdot 57 ; 5 \cdot 81$ & $4 \cdot 92-6 \cdot 29$ \\
\hline \multicolumn{4}{|l|}{ Skinfolds } \\
\hline Triceps (mm) & $13 \cdot 3$ & $11 \cdot 7 ; 14.9$ & $7 \cdot 2-24 \cdot 7$ \\
\hline Biceps (mm) & $6 \cdot 6$ & $5 \cdot 8 ; 7 \cdot 4$ & $3 \cdot 1-15 \cdot 1$ \\
\hline Subscapula (mm) & $10-3$ & $9 \cdot 3 ; 11 \cdot 3$ & $6 \cdot 0-16 \cdot 9$ \\
\hline Suprailiac (mm) & $7 \cdot 4$ & $6 \cdot 3 ; 8 \cdot 5$ & $3 \cdot 7-16 \cdot 5$ \\
\hline Midthigh (mm) & $22 \cdot 6$ & $20 \cdot 4 ; 24 \cdot 8$ & $10 \cdot 5-35 \cdot 5$ \\
\hline \multicolumn{4}{|l|}{ Bioimpedance } \\
\hline Height $^{2} /$ resistance & $45 \cdot 3$ & $43 \cdot 7 ; 46.9$ & $32 \cdot 4-54 \cdot 3$ \\
\hline
\end{tabular}

TBMC, total bone-mineral content; DXA, dual-energy X-ray absorptiometry.

* Calculated as: $(\mathrm{TBMC} /(0 \cdot 824 \times$ weight $)) \times 100$.

Table 2 . Body fat content ( $\%$ body weight) in thirty-four young women: comparison of results from the criterion method (three-compartment model $(3 C)$ with underwater weighing $(U W W)$ and dual energy $X$-ray absorptiometry $(D X A))$ and the alternatives: $U W W, D X A$, two skinfold equations and two bioimpedance $(B I A)$ equations

\begin{tabular}{|c|c|c|c|}
\hline & Mean & $95 \% \mathrm{CI}$ & Range \\
\hline \multicolumn{4}{|l|}{ Body fat $(\%)$} \\
\hline $3 \mathrm{C}$ & $22 \cdot 7$ & $20 \cdot 8 ; 24 \cdot 6$ & $13 \cdot 5 \cdot 31 \cdot 1$ \\
\hline UWW & $22 \cdot 2$ & $20 \cdot 7 ; 23 \cdot 7$ & $14 \cdot 0-30 \cdot 7$ \\
\hline DXA & $30 \cdot 0$ & $27 \cdot 8 ; 32 \cdot 2$ & $17 \cdot 0-41 \cdot 6$ \\
\hline Skinfolds $_{\text {JPW }}$ & $17 \cdot 4$ & $15.9 ; 18.9$ & $10 \cdot 1-28 \cdot 3$ \\
\hline Skinfolds $_{\text {DW }}$ & $17 \cdot 2$ & $16.4 ; 18.0$ & $12 \cdot 3-21 \cdot 9$ \\
\hline BIA $_{\mathrm{LUK}}$ & $24 \cdot 1$ & $22 \cdot 3 ; 25 \cdot 9$ & $14 \cdot 0-30 \cdot 7$ \\
\hline $\mathrm{BIA}_{\mathrm{DEU}}$ & $27 \cdot 2$ & $26.4 ; 28 \cdot 0$ & $22 \cdot 3-30 \cdot 9$ \\
\hline \multicolumn{4}{|c|}{ Alternative minus $3 \mathrm{C}(\mathrm{BF} \%)$} \\
\hline UWW* & -0.5 & $-1 \cdot 0 ;-0.02$ & $-3 \cdot 1$ to $+2 \cdot 6$ \\
\hline DXA & $7 \cdot 3$ & $5 \cdot 8 ; 8 \cdot 8$ & -6.7 to $+15 \cdot 1$ \\
\hline Skinfolds $_{\mathrm{JPW}}$ & $-5 \cdot 3$ & $-6 \cdot 6 ;-4 \cdot 1$ & $-16 \cdot 2$ to $+2 \cdot 8$ \\
\hline Skinfolds $_{\mathrm{Dw}}{ }^{*}$ & -5.5 & $-7.0 ;-4.0$ & -15.8 to +3.8 \\
\hline $\mathrm{BIA}_{\mathrm{LUK}}$ & $1 \cdot 5$ & $0.1 ; 2 \cdot 9$ & $-11 \cdot 0$ to $+10 \cdot 3$ \\
\hline $\mathrm{BIA}_{\mathrm{DEV}} *$ & $4 \cdot 5$ & $3 \cdot 1 ; 5 \cdot 9$ & -3.9 to +12.4 \\
\hline
\end{tabular}

BF \%, percentage body fat; JPW, equation of Jackson et al. (1980); DW, equation of Durnin \& Womersley (1974); LUK, equation of Lukaski et al. (1986); DEU, equation of Deurenberg et al. (1990).

* Difference was dependent on the size of measurement.

differences from the $3 \mathrm{C}$ model (overestimation by DXA and BIA $\mathrm{LUK}_{\mathrm{K}}$, underestimation by skinfolds $_{J P W}$ ) were of a similar magnitude in both lean and normal-weight subjects.

The correlation between the $3 \mathrm{C}$ model and UWW was strong with a small SEE (Table 2). The correlations between the $3 \mathrm{C}$ and the remaining alternative methods (DXA, skinfolds, BIA) were lower and the SEE larger. 
Table 3. Body fat content ( $\%$ body weight) in thirty-four young women: correlations of the criterion method (3-compartment model with underwater weighing (UWW) and dual energy $X$-ray absorptiometry $(D X A))$ with alternatives: $U W W, D X A$, two skinfold equations and two bioimpedance (BIA) equations

\begin{tabular}{llll}
\hline \hline & $r$ & $95 \%$ CI & SEE (BF\%) \\
\hline UWW & 0.96 & $0.92 ; 0.98$ & 1.49 \\
DXA & 0.74 & $0.54 ; 0.86$ & 3.57 \\
Skinfolds & 0.68 & $0.44 ; 0.83$ & 3.89 \\
Skinfolds $_{\text {Dw }}$ & 0.62 & $0.36 ; 0.80$ & 4.17 \\
BIA $_{\text {LU }}$ & 0.68 & $0.44 ; 0.83$ & 3.89 \\
BIA $_{\text {DEU }}$ & 0.66 & $0.41 ; 0.82$ & 3.96 \\
\hline \hline
\end{tabular}

SEE, standard error of the estimate; BF \%, percentage body fat; JPW, equation of Jackson et al. (1980); DW, equation of Durnin \& Womersley (1974); LUK, equation of Lukaski et al. (1986); DEU, equation of Deurenberg et al. (1990).
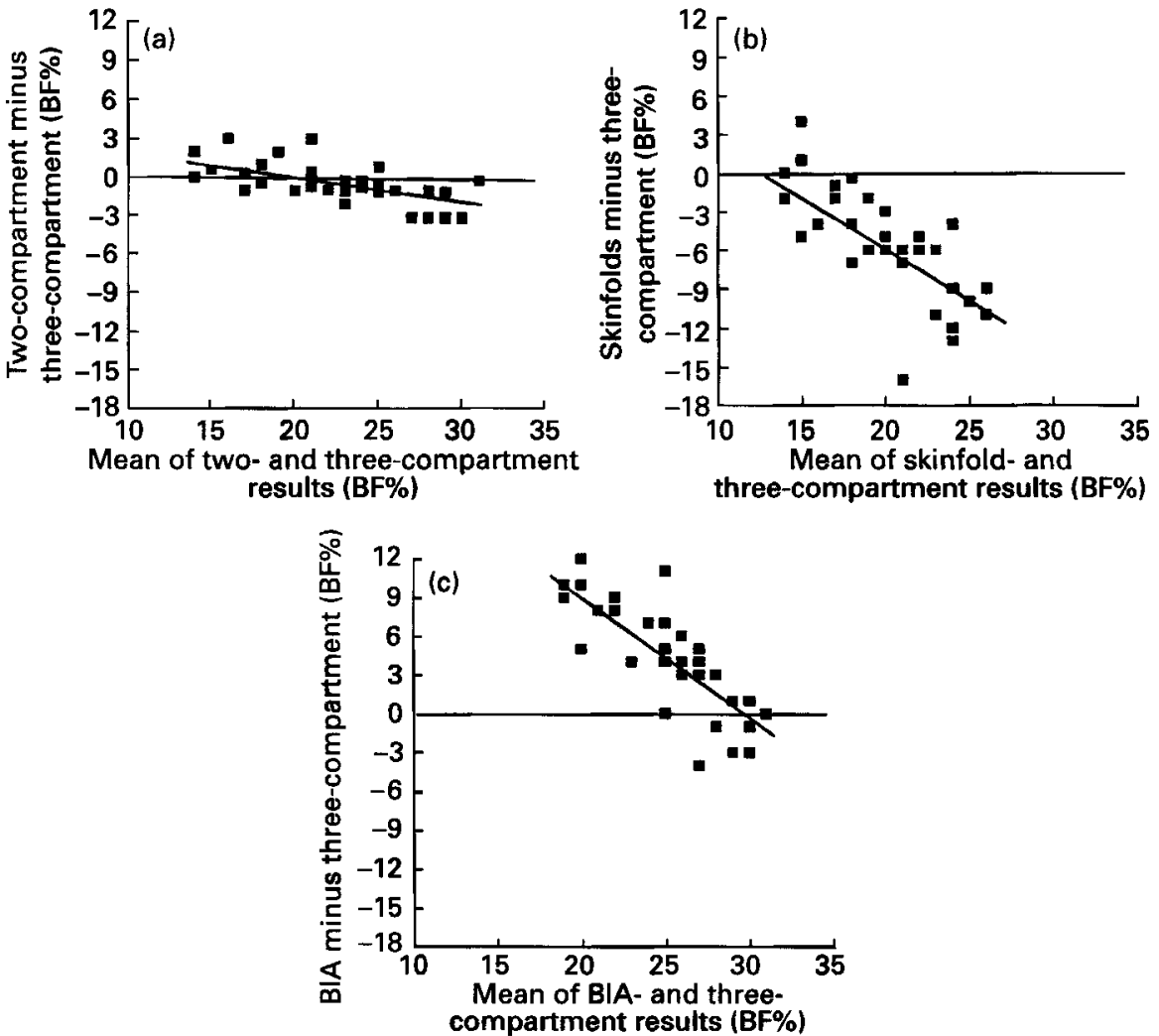

Fig. 1. Comparison between a three-compartment model and (a) a two-compartment model (underwater weighing) $(y=3 \cdot 7-0 \cdot 19 x)$, (b) skinfolds (Durnin \& Womersley, 1974) $(y=12.6-0.91 x)$ and (c) bioimpedance (Deurenberg et al. 1990) $(y=28 \cdot 0-0.94 x)$ for measuring body composition. The figure illustrates a significant relationship between the difference of the methods (alternative minus the three-compartment model) and their mean in thirty-four young women. 


\section{DISCUSSION}

\section{Underwater weighing and dual-energy $X$-ray absorptiometry}

A 3C model (fat, bone and fat-free soft tissue measured with UWW and DXA) for body composition was used as the criterion to evaluate the relative accuracy of two laboratory (UWW, DXA) and two 'field ' methods (skinfolds, BIA). Most (65\%) of our subjects were female athletes on a high national level. Overweight $\left(B M I \geqslant 25 \mathrm{~kg} / \mathrm{m}^{2}\right)$ subjects were excluded.

The 3C model (Lohman, 1986), with body density measured by UWW and specific adjustment for variation in TBMC, was chosen as the criterion. Nevertheless, the accuracy of this method is dependent on several assumptions. Therefore, an individual's true body composition remains unknown even when such a multicompartment model is used.

RV was measured while the subject was in the water tank, but not simultaneously with the weighing. Differences between the measured RV and the actual lung volume during the weighing might cause errors in assessment of body composition. We tried to reduce this error by taking the mean value of two to four RV measurements, and by using the three highest underwater weights (with lung volume as close to RV as possible) in calculations.

It was not possible to measure total body water by stable-isotope techniques in the present study. Consequently, we could not use a four-compartment model which might be considered a limitation. Nevertheless, during certain periods in women's life (early adulthood, after the menopause), interindividual variation in TBMC is apparently the most important source of bias in body composition assessment (Martin \& Drinkwater, 1991; Vogel \& Friedl, 1992). Moreover, by timing the measurements according to the participants' menstruation, we controlled for the episodic increases in total body water during different phases of the menstrual cycle (Vogel \& Friedl, 1992).

A matter of debate is whether bone (or body) mineral content should be related to body weight (Lohman, 1986; Friedl et al. 1992) or to FFM (Wang et al. 1989; Snead et al. 1993). The latter approach seems logical, because TBMC affects the density of FFM, which then alters calculations of BF\%. When FFM is used as a correction factor for UWW, FFM should be measured with an alternative method, such as DXA (Snead et al. 1993). However, because of the large difference between UWW and DXA results for BF \% in the present study, we were unwilling to express TBMC as a fraction of $\mathrm{FFM}_{\mathrm{DXA}}$. If, as seemed obvious, DXA overestimated $\mathrm{BF} \%, \mathrm{FFM}_{\mathrm{DxA}}$ results would have been underestimations. This would have increased the mineral fraction artifically and affected the accuracy of the $3 \mathrm{C}$ model.

The assumption that TBMC represents $82.4 \%$ of total body minerals (Brozek et al. 1963) is not necessarily correct. For instance, using neutron activation analysis, UWW and dualphoton absorptiometry, Heymsfield et al. (1989) found TBMC to be about $87 \%$ of body minerals. Moreover, the ratio between body and bone minerals is not essentially similar in people with large differences in body frame. Unfortunately, we did not find a $3 \mathrm{C}$ model with TBMC as a fraction of body weight. We considered the potential bias associated with $\mathrm{FFM}_{\mathrm{DXA}}$ measurement to have a greater impact on the $3 \mathrm{C}$ model than the assumed ratio between TBMC and true total body-mineral content.

The mean difference in $\mathrm{BF} \%$ between UWW and the $3 \mathrm{C}$ model was rather small $(0.5$ percentage units or $2.2 \%$ ). Nevertheless, we found an association between $\mathrm{BF} \%$ and the difference: compared with the $3 \mathrm{C}$ model, UWW showed a tendency to overestimate $\mathrm{BF} \%$ in lean and underestimate $\mathrm{BF} \%$ in normal-weight subjects. This implies that the body mineral fraction was smaller in lighter subjects.

Bunt et al. (1990) estimated the theoretical differences between models with and without 
adjustment for bone minerals to be about 2.5 percentage units $(5-6 \%)$ in those female athletes whose bone density deviated most from the mean. Our divergence for the lean subjects (0.65 percentage units) was smaller than found by Bunt et al. (1990) which might be explained by the fact that they included subjects with secondary amenorrhoea.

There has been considerable interest concerning the validity of DXA in BF\% assessment. We found a large systematic difference (overestimation) between DXA and the 3C model. Moreover, the random discrepancies (based on correlation and SEE for DXA against the $3 \mathrm{C}$ model) were of similar magnitude as found for less expensive and faster field methods, i.e. skinfolds and BIA. Hence, we do not regard DXA as superior to either of the field methods in assessment of BF \%.

The difference between DXA and the criterion model (UWW, three or four compartments) has been proposed to be due to several factors, including subjects' sex, age, BF \% and the DXA instrument (manufacturer, version of software, X-ray spectrum, calibration standards) used for measurement (Pritchard et al. 1993; Snead et al. 1993). The number of method comparisons with Norland XR-26 is limited. Clark et al. (1993) found XR-26 to overestimate BF\% in adult males by 3.9 percentage units, with UWW as the criterion. The large overestimation in the present study, independent of $\mathrm{BF} \%$ within the range of lean and normal-weight women, was in agreement with the apparent systematic bias in Norland software converting the raw scan data to BF \%, as suggested by Clark et al. (1993). We are not aware of any technical explanations for this bias.

\section{Skinfold thicknesses and bioelectrical impedance}

The quadratic skinfold equations by Jackson et al. (1980) have been proposed to be the most appropriate for field assessment of body composition in physically active women (Wilmore, 1992; Webster \& Barr, 1993). In comparison with UWW (Graves et al. 1987; Clark et al. 1993; Eaton et al. 1993) or BIA (Graves et al. 1987; Eaton et al. 1993; Webster \& Barr, 1993), the equations by Jackson et al. (1980) appear to give lower BF \% estimations for females, thus agreeing with our results.

In contrast to our results, higher $\mathrm{BF} \%$ estimations were obtained when Durnin \& Womersley (1974) equations were used against UWW or BIA in adult women (McNeill et al. 1991; Pritchard et al. 1993). It is clear that the age of the subjects, different measuring techniques and skinfold calipers affect the results. More interesting, however, was that the two equations used in the present study showed a different association with the size of the measurement. The skinfold sites of Durnin \& Womersley (1974) did not include thigh, which is an important fat store of women with normal or high fat mass.

Choice of the regression equation also affects BF\% results obtained from BIA. A difficulty when measuring women during their early adulthood is to choose between adult and child equations. In the present study the sex-specific adult equation of Lukaski et al. (1986) gave higher BF\% values compared with all other methods except DXA and BIA $_{\text {DEU }}$. The child equation of Deurenberg et al. (1990) originated from girls aged 13-25 years, and from boys aged 16-25 years. The inclusion of age and sex (zero for girls) is thought to adjust for variations in FFM hydration, distribution between intra- and extracellular water and decreasing amounts of electrolytes in the tissues during maturation. The present results suggest that the Deurenberg et al. (1990) equation 'overadjusted' for effects of maturation in lean subjects, in particular.

Recently, Webster \& Barr (1993) compared four different BIA equations to assess BF \% in female athletes aged 12-17 years. They found that an equation specific for children gave higher values $(25 \cdot 2 \%)$ than the three other equations $(17 \cdot 5,20 \cdot 2$ and $22 \cdot 7 \%)$. Three other 
comparisons between BIA from RJL Systems and the criterion (UWW) support our findings on overprediction of BF \% in lean women (Graves et al. 1987; Gray et al. 1990; Pritchard et al. 1993).

\section{CONCLUSIONS}

In the present study we compared two laboratory methods (UWW and DXA) and four field methods (two skinfold and two BIA equations) to assess BF \% against the $3 \mathrm{C}$ model (fat, fat-free soft tissue, bone) in young, predominantly athletic women, with $\mathrm{BF} \%$ values ranging from 13.5 to $31 \cdot 3$. We review our study with the following conclusions: (1) on average, the difference between UWW and the $3 \mathrm{C}$ model was small. Compared with the $3 \mathrm{C}$ model, DXA and both BIA equations clearly overestimated, and both skinfold equations underestimated, $\mathrm{BF} \%$. Based on a significant mean difference from the $3 \mathrm{C}$ model and a large SEE, we do not regard DXA as superior to skinfolds or BIA to assess BF \%; (2) the difference between the $3 \mathrm{C}$ model and three alternatives (UWW, skinfolds ${ }_{\mathrm{DW}}$ and $\mathrm{BIA} \mathrm{A}_{\mathrm{DEU}}$ ) correlated negatively with $\mathrm{BF} \%$ (mean of the alternative and the $3 \mathrm{C}$ model). This association induced an overestimation of $\mathrm{BF} \%$ in the lean subjects $\left(\mathrm{BIA}_{\mathrm{LUK}}\right)$, an underestimation of $\mathrm{BF} \%$ in normal-weight subjects (skinfolds $\mathrm{DW}_{\mathrm{W}}$ ), or both (UWW). Consequently, the use of these alternative methods instead of the $3 \mathrm{C}$ model would reduce the obtained range of $B F \%$. The discrepancy between the remaining alternatives (DXA, skinfolds $_{\mathrm{JPW}}$ and $\left.\mathrm{BIA} \mathrm{A}_{\mathrm{LUK}}\right)$ and the $3 \mathrm{C}$ model was independent of $\mathrm{BF} \%$.

The technical assistance of Ulla Hakala, Kirsti Malmivuo, Virpi Nieminen and Kirsi Turtonen is highly appreciated.

\section{REFERENCES}

Altman, D. G. \& Bland, J. M. (1983). Measurement in medicine: the analysis of method comparison studies. Statistician 32, 307-317.

Brozek, J., Grande, F., Anderson, J. T. \& Kemp, A. (1963). Densitometric analysis of body composition: revision of some quantitative assumptions. Annals of the New York Academy of Sciences 110, 113-140.

Bunt, J. C., Going, S. C., Lohman, T. G., Heinrich, C. H., Perry, C. D. \& Pamenter, R. W. (1990). Variation in bone mineral content and estimated body fat in young adult females. Medicine and Science in Sports and Exercise 22, 564-569.

Clark, R. R., Kuta, J. M. \& Sullivan, J. C. (1993). Prediction of percent body fat in adult males using dual energy $\mathrm{X}$-ray absorptiometry, skinfolds, and hydrostatic weighing. Medicine and Science in Sports and Exercise 25, 528-535.

Deurenberg, P., Kusters, C. S. L. \& Smith, H. E. (1990). Assessment of body composition by bioelectrical impedance in children and young adults is strongly age-dependent. European Journal of Clinical Nutrition 44, 261-268.

Durnin, J. V. G. A. \& Womersley, J. (1974). Body fat assessed from total body density and its estimation from skinfold thickness: measurements on 481 men and women aged from 16 to 72 years. British Journal of Nutrition 32, 77-97.

Eaton, A. W., Israel, R. G., O'Brien, K. F., Hortobagyi, T. \& McCammon, M. R. (1993). Comparison of four methods to assess body composition in women. European Journal of Clinical Nutrition 47, 353-360.

Friedl, K. E., DeLuca, J. P., Marchitelli, L. J. \& Vogel, J. A. (1992). Reliability of body-fat estimations from a four-compartment model by using density, body water, and bone mineral measurements. American Journal of Clinical Nutrition 55, 764-770.

Gardner, M. J. \& Altman, D. B. (1989). Statistics With Confidence-Confidence Intervals and Statistical Guidelines. London: British Medical Journal Publications.

Graves, J. E., Pollock, M. L. \& Sparling, P. B. (1987). Body composition of elite female runners. International Journal of Sports Medicine 8, 96-102.

Gray, D. S., Bray, G. A., Bauer, M., Kaplan, K., Gemayel, N., Wood, R., Greenway, F. \& Kirk, S. (1990). Skinfold thickness measurements in obese subjects. American Journal of Clinical Nutrition 51, $571-577$.

Harrison, G. G., Buskirk, E. R., Carter, J. E. L., Johnston, F. E., Lohman, T. G., Pollock, M. L., Roche, A. F. \& Wilmore, J. (1991). Skinfold thicknesses and measurement technique. In Anthropometric Standardization 
Reference Manual, abridged edition, pp. 55-70 [T. G. Lohman, A. F. Roche and R. Martorell, editors]. Champaign, IL: Human Kinetics.

Heymsfield, S. B., Wang, J., Kehayias, J., Heshka, S., Lichtman, S. \& Pierson, R. N. Jr (1989). Chemical determination of human body density in vivo: relevance to hydrodensitometry. American Journal of Clinical Nutrition 50, 1282-1289.

Jackson, A. S., Pollock, M. L. \& Ward, A. (1980). Generalized equations for predicting body density of women. Medicine and Science in Sports and Exercise 12, 175-182.

Lohman, T. G. (1986). Applicability of body composition techniques and constants for children and youth. In Exercise and Sport Science Reviews, vol. 14, pp. 325-357 [K. E. Randolf, editor]. New York: Macmillan.

Lukaski, H. C., Bolonchuk, W. W., Hall, C. B. \& Siders, W. A. (1986). Validation of tetrapolar bioelectric impedance method to assess human body composition. Journal of Applied Physiology 60, 1327-1332.

Lukaski, H. C., Johnson, P. E., Bolonchuk, W. W. \& Lykken, G. I. (1985). Assessment of fat-free mass using bioelectrical impedance measurements of the human body. American Journal of Clinical Nutrition 41, 810-817.

McNeill, G., Fowler, P. A., Maughan, R. J., McGaw, B. A., Fuller, M. F., Gvozdanovic, D. \& Gvozdanovic, S. (1991). Body fat in lean and overweight women estimated by six methods. British Journal of Nutrition 65, 95-103.

Martin, A. D. \& Drinkwater, D. T. (1991). Variability in measures of body fat. Assumptions or technique? Sports Medicine 11, 277-288.

Mazess, R. B., Barden, H. S., Bisek, J. P. \& Hanson, J. (1990). Dual-energy X-ray absorptiometry for total-body and regional bone-mineral and soft-tissue composition. American Journal of Clinical Nutrition 51, 1106-1112.

Pritchard, J. E., Nowson, C. A., Strauss, B. J., Carlson, J. S., Kayamakci, B. \& Wark, J. D. (1993). Evaluation of dual energy X-ray absorptiometry as a method of measurement of body fat. European Journal of Clinical Nutrition 47, 216-228.

Siri, W. E. (1956). The gross composition of the body. In Advances in Biological and Medical Physics, pp. 239-280 [C. A. Tobias and J. H. Lawrence, editors]. New York: Academic Press.

Snead, D. S., Birge, S. \& Kohrt, W. M. (1993). Age-related differences in body composition by hydrodensitometry and dual-energy X-ray absorptiometry. Journal of Applied Physiology 74, 770-775.

Suominen, H. (1993). Bone mineral density and long term exercise. An overview of cross-sectional athlete studies. Sports Medicine 16, 316-330.

Vogel, J. A. \& Friedl, K. E. (1992). Body fat assessment in women. Special considerations. Sports Medicine 13, 245-269.

Wang, J., Heymsfield, S. B., Aulet, M., Thornton, J. C. \& Pierson, R. N. Jr (1989). Body fat from body density: underwater weighing vs. dual-photon absorptiometry. American Journal of Clinical Nutrition 256, E829-E834.

Webster, B. L. \& Barr, S. I. (1993). Body composition analysis of female adolescent athletes: comparing six regression equations. Medicine and Science in Sports and Exercise 25, 648-653.

Wilmore, J. (1992). Body weight and body composition. In Eating, Body Weight and Performance in Athletes, pp. 77-93 [K. D. Brownell, J. Rodin and J. H. Wilmore, editors]. Philadelphia: Lea \& Febinger. 